\title{
Pi treatment for the constituent rectangles of the superscribed square in the study of exact area of the inscribed circle and its value of Pi (SV University Method")
}

\author{
R.D. Sarva Jagannadha Reddy
}

\begin{abstract}
Pi value equal to 3.14159265358... is derived from the Exhaustion method of Archimedes (240 BC) of Syracuse, Greece. It is the only one geometrical method available even now. The second method to compute $3.14159265358 \ldots$ is the infinite series. These are available in larger numbers. The infinite series which are of different nature are so complex, they can be understood and used to obtain trillion of decimals to $3.14159265358 \ldots$ with the use of super computers only. One unfortunate thing about this value is, it is still an approximate value. In the present study, the exact $\pi$ value is obtained. It is $\frac{14-\sqrt{2}}{4}=3.14644660942 \ldots A$ different approach is followed here by the blessings of the God. The areas of constituent rectangles of the superscribed square, are estimated both arithmetically, and in terms of $\pi$ of the inscribed circle. And $\pi$ value thus derived from this study of correct relationship among superscribed square, inscribed circle and constituent rectangles of the square, is exact.
\end{abstract}

Keywords: Circle, diagonal, diameter, area, radius, side, square

\section{Introduction}

Square is an algebraic geometrical entity. It has four sides and two diagonals which are straight lines. A circle can be inscribed in the square. The side of the square and the diameter of the inscribed circle are same. This similarity between diameter and side, has made possible to find out the exact length of the circumference and the exact extent of the area of the circle, when this interrelationship between circle and its superscribed square, are understood in their right perspective. The difficulty is, the inscribed circle is a curvature, though, its diameter/ radius is a straight line as in the case of side, diagonal of the square. When we say a different approach is adopted, it means, these are entirely new to the literature of mathematics. The universal acceptance to the new principles observed in the following method is a tough job and takes time. However, as the following reasoning ways are cent percent in accordance with the known principles, understanding of the idea is easy.

To study the different dimensions, such as, circumference and area of circle, $\pi$ constant is inevitable. Similarly, to understand perimeter and area of the square, $4 \mathrm{a}$ and $\mathrm{a}^{2}$ are adopted and hence, no constant similar to circle is necessary in square. In the present study, the area of the square is divided into five rectangles. The areas of rectangles are calculated in two ways: they are: 1. Arithmetical way and 2. In terms of $\boldsymbol{\pi}$ of the inscribed circle. Finally, the arithmetical values are equated to formulas having $\pi$, and the value of $\pi$ is derived ultimately, which is exact.

\section{Procedure}

Draw a square and its two diagonals. Inscribe a circle in the square.

1. $\quad$ Square $=\mathrm{ABCD}, \mathrm{AB}=\mathrm{Side}=\mathrm{a}$

2. Diagonals $=\mathrm{AC}=\mathrm{BD}=\sqrt{2} \mathrm{a}$

3. ' $\mathrm{O}$ ' Centre, $\mathrm{EF}=$ diameter $=$ side $=\mathrm{a}$

4. The circumference of the circle intersects two diagonals of four points: E, H, F and G. Draw a parallel line $\mathrm{IJ}$ to the sides $\mathrm{DC}$, passing through $\mathrm{G}$ and $\mathrm{F}$.

5. $\mathrm{OG}=\mathrm{OF}=$ radius $=\mathrm{a} / 2$

6. Triangle GOF. $\mathrm{GF}=$ hypotenuse $=\mathrm{OG} \times \sqrt{2}=\frac{\mathrm{a}}{2} \times \sqrt{2}=\frac{\sqrt{2} \mathrm{a}}{2}=\mathrm{GF}$

\footnotetext{
* This author studied B.Sc., (Zoology as Major) and M.Sc., (Zoology) during the years 1963-68 in the Sri Venkateswara University College, Tirupati, Chittoor district, Andhra Pradesh, India. And hence this author as a mark of his gratitude to the Alma Mater, this method is named after University's Honour.
} 
7. $\mathrm{IJ}=$ side $=\mathrm{a}$

8. $\mathrm{DI}=\mathrm{IG}=\mathrm{FJ}=\mathrm{JC}=\frac{\text { Side }- \text { hypotenuse }}{2}=\frac{\mathrm{IJ}-\mathrm{GF}}{2}$

$=\left(\mathrm{a}-\frac{\sqrt{2} \mathrm{a}}{2}\right) \frac{1}{2}=\left(\frac{2-\sqrt{2}}{4}\right) \mathrm{a}=\mathrm{JC}$

9. $\mathrm{JC}=\left(\frac{2-\sqrt{2}}{4}\right) \mathrm{a}, \quad \mathrm{CB}=$ side $=\mathrm{a}$

$\mathrm{JB}=\mathrm{CB}-\mathrm{CJ}=\mathrm{a}-\left(\frac{2-\sqrt{2}}{4}\right) \mathrm{a}=\left(\frac{2+\sqrt{2}}{4}\right) \mathrm{a}$

10. Bisect JB twice of CB side of Fig-2

$\mathrm{JB} \rightarrow \mathrm{JL}+\mathrm{LB} \rightarrow \mathrm{JK}+\mathrm{KL}+\mathrm{LM}+\mathrm{MB}$

$=\left(\frac{2+\sqrt{2}}{4}\right) \mathrm{a} \rightarrow\left(\frac{2+\sqrt{2}}{8}\right) \mathrm{a} \rightarrow\left(\frac{2+\sqrt{2}}{16}\right) \mathrm{a}$
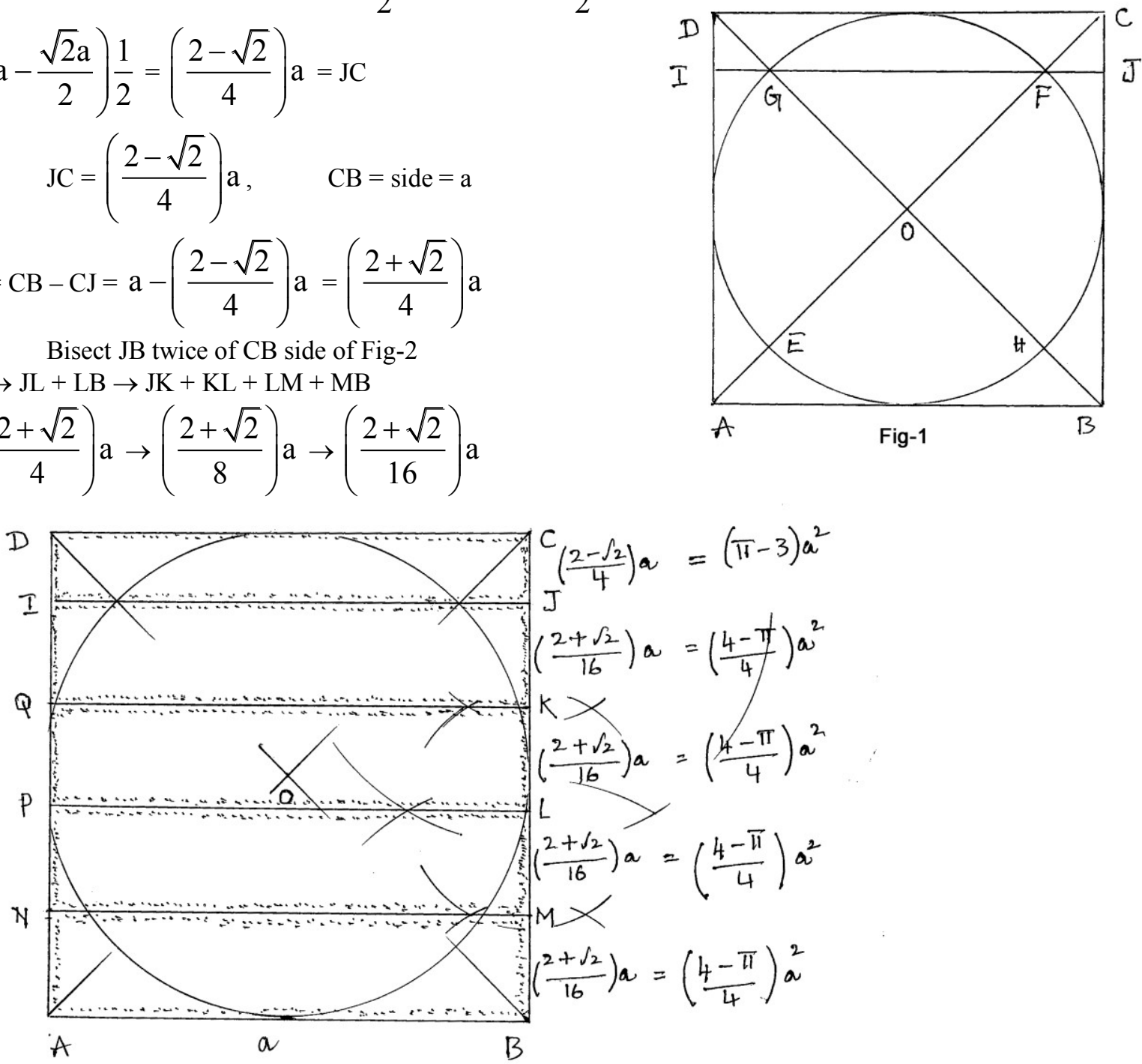

Fig-2

11. Similarly, bisect IA twice, of AD side of Fig-2

$\mathrm{IA} \rightarrow \mathrm{IP}+\mathrm{PA} \rightarrow \mathrm{IQ}+\mathrm{QP}+\mathrm{PN}+\mathrm{NA}$

12. Join QK, PL, and NM.

13. Finally, the ABCD square is divided into five rectangles.

DIJC, IQKJ, QPLK, PNML and NABM

Out of the five rectangles, the uppermost rectangle DIJC is of different dimension from the other four bottomed rectangles.

14. Area of DIJC rectangle

$=\mathrm{DI} \times \mathrm{IJ}=\left(\frac{2-\sqrt{2}}{4}\right) \mathrm{a} \times \mathrm{a}=\left(\frac{2-\sqrt{2}}{4}\right) \mathrm{a}^{2}$

15. The lower four rectangles are of same area. For example one rectangle

$=\mathrm{IQKJ}=\mathrm{IQ} \times \mathrm{QK}=\left(\frac{2+\sqrt{2}}{16}\right) \mathrm{a} \times \mathrm{a}=\left(\frac{2+\sqrt{2}}{16}\right) \mathrm{a}^{2}$

16. Area of 4 rectangles 
$=\mathrm{IQKJ}+\mathrm{QPLK}+\mathrm{PNML}+\mathrm{NABM}=4\left(\frac{2+\sqrt{2}}{16}\right) \mathrm{a}^{2}=\left(\frac{2+\sqrt{2}}{4}\right) \mathrm{a}^{2}$

17. Area of the square $\mathrm{ABCD}$

$=$ DIJC +4 bottomed rectangles $=\mathrm{a}^{2}$

$=\left(\frac{2-\sqrt{2}}{4}\right) \mathrm{a}^{2}+4\left(\frac{2+\sqrt{2}}{16}\right) \mathrm{a}^{2}=\mathrm{a}^{2}$

18. Let us repeat that

\section{Part-II}

Area of the $\mathrm{ABCD}$ square $=\mathrm{a}^{2}$

Area of the inscribed circle $=\frac{\pi \mathrm{d}^{2}}{4}=\frac{\pi \mathrm{a}^{2}}{4} ;$ where diameter $=\mathrm{side}=\mathrm{a}$

19. When side $=$ diameter $=\mathrm{a}=1$

Area of the ABCD square $=\mathrm{a}^{2}=1 \times 1=1$

Area of the inscribed circle $=\frac{\pi \mathrm{d}^{2}}{4}=\frac{\pi \mathrm{a}^{2}}{4}=\frac{\pi \times 1 \times 1}{4}=\frac{\pi}{4}$

20. Corner area in the square (of Figs 1, 2, and 3)

$=$ Square area - circle area

$=1-\frac{\pi}{4}=\frac{4-\pi}{4}$

21. It is true that any bottomed 4 rectangles, is equal to the corner area of the square of Figs 1,2 and 3. Thus,

bottomed rectangle $=$ corner area

$$
\left(\frac{2+\sqrt{2}}{16}\right) \mathrm{a}^{2} \quad=\left(\frac{2+\sqrt{2}}{16}\right) \times 1 \times 1=\frac{2+\sqrt{2}}{16}
$$

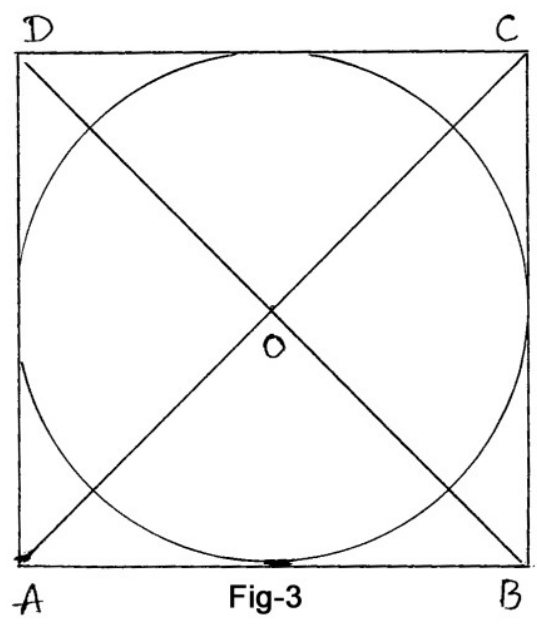

22. Let us prove it i.e. S. No. 21

\section{Part-III}

23. The inscribed circle is equal to the sum of the areas of upper most rectangle DIJC $=\left(\frac{2-\sqrt{2}}{4}\right) \mathrm{a}^{2}$ of S.No. 14 and next lower 3 rectangles IQJK, QPLK and PNML, and each is equal to $\left(\frac{2+\sqrt{2}}{16}\right) \mathrm{a}^{2}$ of S.No. 15 $\left(\frac{2-\sqrt{2}}{4}\right) \mathrm{a}^{2}+3\left(\frac{2+\sqrt{2}}{16}\right) \mathrm{a}^{2}=\left(\frac{14-\sqrt{2}}{16}\right) \mathrm{a}^{2}=\frac{\pi \mathrm{a}^{2}}{4}$

24. Area of the inscribed circle $=\frac{\pi \mathrm{a}^{2}}{4}=\frac{\pi}{4} \quad$ where $\mathrm{a}=1$

Area of the corner region $=\left(\frac{4-\pi}{4}\right)$

Area of the inscribed circle + corner area $=$ square area

$$
\frac{\pi}{4}+\frac{4-\pi}{4}=1
$$

25. The sum of the areas of 4 bottomed rectangles

$=$ Square area - Uppermost rectangle DIJC 
$=\mathrm{a}^{2}-\left(\frac{2-\sqrt{2}}{4}\right) \mathrm{a}^{2}=\left(\frac{2+\sqrt{2}}{4}\right) \mathrm{a}^{2}$ and
S. No. 14
this is equal to S.No. 16

26. As the area of the corner region is equal to any one of the 4 bottomed rectangles,

then it is $=\left(\frac{4-\pi}{4}\right) \mathrm{a}^{2}$

(S.No. $20 \& 21$ )

27. Then the sum of the areas of 4 bottomed rectangles

$=4\left(\frac{4-\pi}{4}\right) \mathrm{a}^{2}=\quad(4-\pi) \mathrm{a}^{2}$

28. Finally,

Area of the uppermost rectangle DIJC

$=$ Square area -4 bottomed rectangles

$=\mathrm{a}^{2}-(4-\pi) \mathrm{a}^{2}=(\pi-3) \mathrm{a}^{2}$

29. CJ length $=(\pi-3) \mathrm{a}$

Side $=\mathrm{AB}=\mathrm{IJ}=\mathrm{a}$

30. Area of the upper most rectangle DIJC

$=\mathrm{CJ} \times \mathrm{IJ}=(\pi-3) \mathrm{a} \times \mathrm{a}=(\pi-3) \mathrm{a}^{2}$

31. Thus, the areas of five rectangles which are interpreted in terms of $\pi$ above, are

> Uppermost rectangle DIJC $=(\pi-3) \mathrm{a}^{2}$

$>\quad 4$ bottomed rectangles $=(4-\pi) \mathrm{a}^{2}$

$>\quad$ Area of the ABCD square

$>\quad$ Uppermost rectangle +4 bottomed rectangles

$=(\pi-3) \mathrm{a}^{2}+(4-\pi) \mathrm{a}^{2}=\mathrm{a}^{2}$

$>\quad$ Area of the inscribed circle

$=$ Uppermost rectangle DIJC +3 bottomed rectangles

$=(\pi-3) \mathrm{a}^{2}+3\left(\frac{4-\pi}{4}\right) \mathrm{a}^{2}=\left(\frac{\pi}{4}\right) \mathrm{a}^{2}$

This is the end of the process of proof.

32. As the corner area is equal to

1. Arithmetically $=\left(\frac{2+\sqrt{2}}{16}\right) \mathrm{a}^{2}=\left(\frac{2+\sqrt{2}}{16}\right) \quad$ S.No. 21 where $\mathrm{a}=1$

and 2. in terms of $\pi=\frac{4-\pi}{4}$

S.No. 20

then $\frac{4-\pi}{4}=\frac{2+\sqrt{2}}{16}$

$\therefore \pi=\frac{14-\sqrt{2}}{4}$

\section{Conclusion}

It is well known, that $\mathrm{a}^{2}$ is the formula to find out area of a square or a rectangle. In this paper besides $\mathrm{a}^{2}$, formulae, in terms of $\pi$, of the inscribed circle in a square, are obtained, and equated to the classical arithmetical values of $\mathrm{a}^{2}$. One has to admire the Nature, that, a circle's area can also be represented exactly equal, by the areas of rectangles, thus, the arithmetical values of these rectangles, are equated to that of a circle, which thus give rise to new $\pi$ value $\frac{14-\sqrt{2}}{4}=3.14644660942 \ldots$ This author stands and bow down and 
dedicates this work to the Nature. The Nature is the visible speck of the infinite Cosmos. The Creator exists in the invisible Energy form of this infinite Cosmos. We call this Creator as GOD and this author offers himself, surrenders himself totally and prays to THE LORD of the Cosmos of His/ Hers/ It's infinite goodness, as an infinitesimally, a small living moving body, as a mark of humble gratitude to THE LORD.

\section{References}

[1]. Lennart Berggren, Jonathan Borwein, Peter Borwein (1997), Pi: A source Book, $2^{\text {nd }}$ edition, Springer-Verlag Ney York Berlin Heidelberg SPIN 10746250.

[2]. Alfred S. Posamentier \& Ingmar Lehmann (2004), $\pi$, A Biography of the World's Most Mysterious Number, Page. 25 prometheus Books, New York 14228-2197.

[3]. RD Sarva Jagannada Reddy (2014), New Method of Computing Pi value (Siva Method). IOSR Journal of Mathematics, e-ISSN: 2278-3008, p-ISSN: 2319-7676. Volume 10, Issue 1 Ver. IV. (Feb. 2014), PP 48-49.

[4]. RD Sarva Jagannada Reddy (2014), Jesus Method to Compute the Circumference of A Circle and Exact Pi Value. IOSR Journal of Mathematics, e-ISSN: 2278-3008, p-ISSN: 2319-7676. Volume 10, Issue 1 Ver. I. (Jan. 2014), PP 58-59.

[5]. RD Sarva Jagannada Reddy (2014), Supporting Evidences To the Exact Pi Value from the Works Of Hippocrates Of Chios, Alfred S. Posamentier And Ingmar Lehmann. IOSR Journal of Mathematics, e-ISSN: 2278-3008, p-ISSN:2319-7676. Volume 10, Issue 2 Ver. II (Mar-Apr. 2014), PP 09-12

[6]. RD Sarva Jagannada Reddy (2014), New Pi Value: Its Derivation and Demarcation of an Area of Circle Equal to Pi/4 in A Square. International Journal of Mathematics and Statistics Invention, E-ISSN: 2321 - 4767 P-ISSN: 2321 - 4759. Volume 2 Issue 5, May. 2014, PP-33-38.

[7]. RD Sarva Jagannada Reddy (2014), Pythagorean way of Proof for the segmental areas of one square with that of rectangles of adjoining square. IOSR Journal of Mathematics, e-ISSN: 2278-3008, p-ISSN:2319-7676. Volume 10, Issue 3 Ver. III (May-Jun. 2014), PP 17-20.

[8]. RD Sarva Jagannada Reddy (2014), Hippocratean Squaring Of Lunes, Semicircle and Circle. IOSR Journal of Mathematics, eISSN: 2278-3008, p-ISSN:2319-7676. Volume 10, Issue 3 Ver. II (May-Jun. 2014), PP 39-46

[9]. RD Sarva Jagannada Reddy (2014), Durga Method of Squaring A Circle. IOSR Journal of Mathematics, e-ISSN: 2278-3008, pISSN:2319-7676. Volume 10, Issue 1 Ver. IV. (Feb. 2014), PP 14-15

[10]. RD Sarva Jagannada Reddy (2014), The unsuitability of the application of Pythagorean Theorem of Exhaustion Method, in finding the actual length of the circumference of the circle and Pi. International Journal of Engineering Inventions. e-ISSN: 2278-7461, pISSN: 2319-6491, Volume 3, Issue 11 (June 2014) PP: 29-35.

[11]. RD Sarva Jagannadha Reddy (2014), Pi of the Circle, at www.rsjreddy.webnode.com 